\title{
Exploratory Factor Analysis of the Self-Compassion Scale- Malay Version: Its Reliability Among Adolescents
}

Nor Azzatunnisak Mohd Khatib, AbRahman Roseliza-Murni, Suzana Mohd Hoesni, Jamiah Manap

To Link this Article: http://dx.doi.org/10.6007/IJARBSS/v11-i3/8916

DOI:10.6007/IJARBSS/v11-i3/8916

Received: 11 January 2021, Revised: 07 February 2021, Accepted: 25 February 2021

Published Online: 10 March 2021

In-Text Citation: (Khatib et al., 2021)

To Cite this Article: Khatib, N. A. M., Roseliza-Murni, A., Hoesni, S. M., \& Manap, J. (2021). Exploratory Factor Analysis of the Self-Compassion Scale-Malay Version: Its Reliability Among Adolescents. International Journal of Academic Research in Business and Social Sciences, 11(3), 36-47.

\section{Copyright: @ 2021 The Author(s)}

Published by Human Resource Management Academic Research Society (www.hrmars.com)

This article is published under the Creative Commons Attribution (CC BY 4.0) license. Anyone may reproduce, distribute, translate and create derivative works of this article (for both commercial and non-commercial purposes), subject to full attribution to the original publication and authors. The full terms of this license may be seen at: http://creativecommons.org/licences/by/4.0/legalcode

Vol. 11, No. 3, 2021, Pg. 36 - 47

Full Terms \& Conditions of access and use can be found at http://hrmars.com/index.php/pages/detail/publication-ethics 


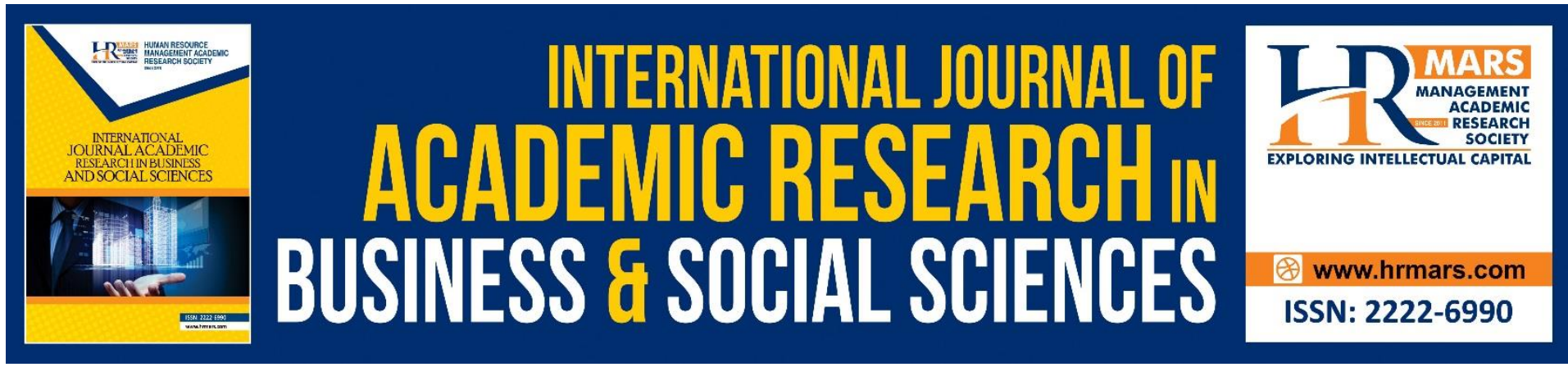

\title{
Exploratory Factor Analysis of the Self- Compassion Scale-Malay Version: Its Reliability Among Adolescents
}

\author{
Nor Azzatunnisak Mohd Khatib, AbRahman Roseliza-Murni, \\ Suzana Mohd Hoesni, Jamiah Manap \\ Center for Research in Psychology and Human Well-Being, Faculty of Social Sciences \& \\ Humanities, Universiti Kebangsaan Malaysia, 43600 Bandar Baru Bangi, Selangor, Malaysia \\ Email: rmurni@ukm.edu.my
}

\begin{abstract}
The purpose of this study is to determine the internal consistency reliability of SelfCompassion Scale-Malay Version (SCS-MV) and its subscale scores among non-clinical youth samples in Malaysia. The original Self Compassion Scale (SCS) comprises of 6 subscales which are self-kindness, self-judgement, common humanity, isolation, mindfulness and overidentification, this scale was translated into Bahasa Melayu (Malay Language) which is the primary language in Malaysia. The Bahasa Melayu translated version of SCS (SCS-MV) was administered on 377 adolescents aged 16 years old who attended secondary school. Exploratory Factor Analysis (EFA) was carried out and Cronbach alphas were used to estimate the reliability or internal consistency of the SCS-MV subscales. Results demonstrated that this study support the use of the six factors scoring method of the original SCS with the overall Cronbach's alpha for SCS-MV ranging from 0.76 to 0.95 . These results provided further psychometric evidence and lent a confirmatory support that SCS-MV can be used among Malay-speaking adolescent populations in Malaysia.
\end{abstract}

Keywords: Exploratory Factor Analysis, Self-Compassion Scale, Reliability, Self-Kindness, SelfJudgement, Common Humanity, Isolation, Mindfulness, Over-Identification

\section{Introduction}

Human life is full of unforeseen circumstances that switch back and forth between sadness and happiness. People may react differently between one another to express their feelings towards a situation. Some might probably feel disappointed with their shortcomings and start to give up (Leary, 2004; Leary et al., 2007). People that have a strong will use the proper mechanism to encounter their negative feelings and struggle to move out from the distressing situations (Leary et al., 2007). One of the mechanisms which is self-compassion has been shown to have impact on the way people think about happiness and well-being (Neff, TóthKirály \& Colosimo, 2018; Raes et al., 2011). This self-compassion construct has also been conceptualized as a coping strategy that promotes positive psychological functioning (Allen, 2010) and consistently linked with positive mental health (Bluth \& Neff, 2018). Results from 
previous studies showed that people who are highly self-compassionate, tend to treat themselves with kindness and concern when encountered the negative events (Allen \& Leary, 2010).

Self-compassion is fundamentally known as an ability to endure one's feelings of suffering or hardship in life with a sense of warmth, connectedness and concern (Kelvin \& Hashimah, 2016; Raes et al., 2011; Sirois, 2014). It is a new concept introduced in social sciences and health research that has been shown to relate to improvement in human life (Leary et al., 2007) and plays a big role in positive psychology (Karakasidou et al., 2017). The self-compassion construct has been studied over the past decades and demonstrated respectable impacts on both adults and adolescents, in terms of increasing self-esteem, subjective well-being, positive affects and life satisfactions (Bluth \& Blanton, 2014; Sirois et al. 2015). It has also been shown to increase emotional flexibility (Beshai, Prentice \& Huang 2018) and happiness (Hollis-Walker \& Colosimo, 2011; Neff \& Costigan, 2014) as well as reducing the risk of mental illness, suicidal ideation and depression (Kaurin, Schönfelder \& Wessa, 2018; Rabon, Sirois, \& Hirsch, 2018). Terry and Leary (2011) further suggested that self-compassion is very important in promoting more effective decision making and achieve long term goals that has been set earlier. Choi, Lee and Lee (2014) postulated that selfcompassion is a form of self-concept that is receiving an increasing attention in the field of psychology.

Presently, the Self-Compassion Scale (SCS) is the only instrument that can measure selfcompassion construct. It was designed to measure six subscales of self-compassion and a total self-compassion score. The scale was developed to explicitly represent the thoughts, emotions and behaviors that were associated with various components of self-compassion (Neff, 2003). The scales comprises of the following components which are: self-kindness, selfjudgement, common humanity, isolation, mindfulness and over-identification. Worldwide, there are many translated versions of SCS available (Costa e. al., 2016; Deniz, Kesici \& Sümer, 2008; Garcia-Campayo et al., 2014; Raes et al., 2011; Neff, 2003; Neff, 2016). Studies on psychometric properties of SCS also demonstrated good internal consistencies across a variety of samples and countries (Cleare, Gumley, Cleare \& O'Connor, 2018; López et al., 2015; Neff, 2003; Raes et al., 2011).

In sum, the extant literature suggested the importance of investigating the selfcompassion contruct as it has been associated with a variety of positive impacts on our lives. However, within the context of Malaysia there is a dearth of research focusing on selfcompassion construct. Examples of the few research on self-compassion conducted in Malaysia were Voon, Lau and Leong (2017); Kelvin and Hashimah (2016). In fact both of these studies suggested that research on self-compassion in Malaysia were not extensively covered and the translated version of SCS in Bahasa Melayu (Malay) version, has lagged far behind (Kelvin \& Hashimah, 2016). Bearing in mind the importance of self-compassion in determining many facets of psychological well-being, it is clear that there is a need to study this construct futher among Malaysian population. For the purpose of local use, it is important that the SCS be translated into Bahasa Melayu, the national language in Malaysia. Hence, this study aims to investigate the factor structure of the Self-Compassion Scale (SCS) originally developed by Neff (2003), but translated it into Bahasa Melayu (Malay) known as SCS-Malay Version (SCS$\mathrm{MV})$. 
This study employed the Exploratory Factor Analysis (EFA), which examined certain group of items that clustered together to represent the SCS-MV subscales. This is in line with suggestions from past researchers (Nor Azzatunnisak, Roseliza-Murni, Suzana \& Jamiah, 2018; Suwaibah, Suzana, Roseliza-Murni \& Zainah, 2016; Siti Fardaniah, 2016; Mohd Effendi, Ahmad Zamri \& Rafidah, 2019; Wan Marina, Mohd Suhaimi \& Sharifa Ezat, 2020) whereby EFA is able to help the researchers to explore the underlying dimensions of the construct being investigated. Muhamud, Engku Ahmad Zaki, Zamri, Hanif and Zaizul (2019) further suggested that an EFA test was used to determine the significance of data and to identify the components that exist in a set of questionnaire. According to Harwati, Melor and Mohamed Amin (2018) EFA is usually employed to validate an instrument as well as to investigate its content validity and check for internal consistency reliability. Mohammad Rahim et al., (2018) and Mohammad Rahim et al., (2017) suggested that we need to run for Kaiser-Meyer-Olkin Measure of Sampling Adequacy and Bartlett's Test of Sphericity first, in order to ensure the appropriateness of conducting EFA.

\section{Method}

\section{Participants}

The participants consisted of 377 adolescents aged 16 years old recruited from secondary schools located in the urban city of Federal Territory, Kuala Lumpur. This sample size was considered enough for conducting the EFA as suggested by Tabachnick, Fidell and Ullman (2007). The sites selected were the metropolitan areas of Malaysia and they represented adolescents from families who migrated from all over Malaysia. Although the Federal Territory of Kuala Lumpur holds the largest economy compared to other states in Malaysia based on gross domestic income and a high standard of living (Department of Statistics Malaysia, 2016), participants in this study represented adolescents from a variety of socioeconomic groups. The selection of participants was in accord with the terms set by the Education Planning and Research Division, Ministry of Education Malaysia (EPRD, MOE), whereby only students who were not going to sit for national examinations were allowed to be recruited in any study. Hence, the form 4 students aged 16 years old attending public schools were recruited in this study.

\section{Measure}

The original Self-Compassion Scale (Neff, 2003) consisted of 26 questions in the form of a 5point Likert scales ranging from 1-5 ( $1=$ almost never to $5=$ almost always). The SCS generates total score of six subscales reflecting the following structures: 1 (self-kindness), 2 (selfjudgement), 3 (common humanity), 4 (isolation), 5 (mindfulness) and 6 (over-identification). The negative item should be reversed coded to get the total mean. Each subscale was added together to get the total mean. High scores indicated that the person was a very compassionate person, while the lower scores indicated low level of self-compassion.

\section{Procedures}

The approval to conduct this study was obtained from the Educational Planning and Research Division, Ministry of Education Malaysia (EPRD, MOE). The permission granted by EPRD was used to obtain the permission for data collection from the school principals. Integrity of translating SCS-MV was verified using the back translation technique (Brislin, 1970). An expert from the educational psychology background and independent translator translated the original SCS (Neff, 2003) into Bahasa Melayu. Then a third person translated this Bahasa 
Melayu version back into English. Any difference in meanings and discrepancies with the original SCS were then adjusted in SCS-MV.

Prior to collecting the data, parents of the participants were consulted for permissions to include their children in this study. During data collection process the school counsellors placed the participants in a mass classroom where they were provided with information sheets about this study and briefed about the purpose of the study, the advantages/disadvantages of participating and the confidentiality of data collected. The participants took about 15 minutes to complete all the questionnaires and they received small tokens upon completing the questionnaires.

All of the completed questionnaires were keyed into SPSS software for analysis. To investigate psychometric properties of SCS-MV, statistical analyses involving checking for normality and sphericity assumptions, the mean scores, standard deviations, skewness and kurtosis of each item were conducted. The internal consistencies were then calculated using the IBM-SPSS AMOS 22. This procedure involved two stages: identifying the descriptive and inferential statistics.

\section{Results}

Our data showed that the EFA revealed six domains/components of self-compassion. Initially, the SCS-MV was measured by the 26 items that were labelled as SCS-MV1 to SCS-MV26. Responses of these items were based on 5-point Likert scale. The mean scores and the standard deviations for each item measuring the self-compassion construct are shown Table 1.

Then, the EFA procedure using Principal Component Analysis (PCA) with Varimax Rotation was carried out on the 26 items of SCS-MV. The findings from Table 2 showed that the Bartlett's Test of Sphericity value was significant $(p<0.05)$. The Measure of Sampling Adequacy by Kaiser-Meyer-Olkin (KMO) $=0.75$ also demonstrated good result, as it was above the minimum value of 0.60 for internal reliability (Awang, 2010; Hoque et al., 2016). Both of these achievements (significant Bartlett's Test and KMO value $>0.6$ ) demonstrated that the data was feasible for the next procedure in the Exploratory Factor Analysis (Awang, 2010; Hoque et al., 2016). 
TABLE 1: Means and standard deviations for the SCS-MV items

Descriptive statistics

\begin{tabular}{lccc}
\hline Item & Mean & $\begin{array}{c}\text { Standard } \\
\text { Deviation }\end{array}$ & $\mathbf{n}$ \\
\hline SCS-MV5 & 4.14 & 1.04 & 377 \\
SCS-MV12 & 3.92 & 0.97 & 377 \\
SCS-MV19 & 4.03 & 1.08 & 377 \\
SCS-MV23 & 4.11 & 1.06 & 377 \\
SCS-MV26 & 4.17 & 0.74 & 377 \\
SCS-MV1 & 3.71 & 0.81 & 377 \\
SCS-MV8 & 3.75 & 0.85 & 377 \\
SCS-MV11 & 3.74 & 0.92 & 377 \\
SCS-MV16 & 3.78 & 0.88 & 377 \\
SCS-MV21 & 3.78 & 0.93 & 377 \\
SCS-MV3 & 3.16 & 0.77 & 377 \\
SCS-MV7 & 3.29 & 0.91 & 377 \\
SCS-MV10 & 3.22 & 0.96 & 377 \\
SCS-MV15 & 3.21 & 0.89 & 377 \\
SCS-MV4 & 3.11 & 0.82 & 377 \\
SCS-MV13 & 3.24 & 0.78 & 377 \\
SCS-MV18 & 3.20 & 0.79 & 377 \\
SCS-MV25 & 2.93 & 0.88 & 377 \\
SCS-MV9 & 2.30 & 1.06 & 377 \\
SCS-MV14 & 2.34 & 1.02 & 377 \\
SCS-MV17 & 2.68 & 1.20 & 377 \\
SCS-MV22 & 3.69 & 0.91 & 377 \\
SCS-MV6 & 3.71 & 0.83 & 377 \\
SCS-MV2 & 3.62 & 0.80 & 377 \\
SCS-MV20 & 3.50 & 0.90 & 377 \\
SCS-MV24 & 3.16 & 0.93 & \\
\hline
\end{tabular}

TABLE 2: Value of KMO and Bartlett's Test KMO dan Bartlett's Test

\begin{tabular}{lcc}
\hline Kaiser-Meyer-Olkin Measure of Sampling Adequacy & 0.75 \\
\hline Bartlett's Test of Sphericity & Approx. Chi-Square & 1903.90 \\
& df & 325 \\
Sig. & 0.000 \\
\hline
\end{tabular}

The total value of variance estimated is essential for us to know the exact percentage of the items that can measure the self-compassion construct. Table 3 showed the total value of variance estimated by the SCS-MV subscales in measuring self-compassion. Details of the results showed that SCS-MV subscales was able to measure self-compassion construct via its six components, namely component 1 (self-kindness) measured $16.32 \%$, component 2 (selfjudgement) $=15.01 \%$, component 3 (common humanity) $=11.03 \%$, component 4 (isolation) $=9.78 \%$, component 5 (mindfulness) $=8.79 \%$ and component 6 (over-identification) measured $8.10 \%$ of the constructs. The total estimated variance for the self-compassion 
construct was $69.07 \%$. This value represented a good confirmatory as it exceeded the minimum requirement of $60 \%$ from the total scale (Awang, 2010; 2012; Hoque et al., 2016).

TABLE 3: Total variance estimated

\begin{tabular}{ccccccc}
\hline \multirow{2}{*}{ Components } & \multicolumn{3}{c}{ Initial Eigenvalues } & \multicolumn{2}{c}{ Rotation Sums of Squared Loadings } \\
\cline { 2 - 7 } & Total & $\begin{array}{c}\text { \% of } \\
\text { Variance }\end{array}$ & $\begin{array}{c}\text { Cumulative } \\
\%\end{array}$ & Total & $\begin{array}{c}\text { \% of } \\
\text { Variance }\end{array}$ & $\begin{array}{c}\text { Cumulative } \\
\%\end{array}$ \\
\hline 1 & 5.54 & 21.30 & 21.30 & 4.25 & 16.36 & 16.36 \\
2 & 3.66 & 14.06 & 35.37 & 3.90 & 15.01 & 31.37 \\
3 & 3.14 & 12.09 & 47.45 & 2.87 & 11.03 & 42.40 \\
4 & 2.37 & 9.10 & 56.55 & 2.54 & 9.78 & 52.18 \\
5 & 1.89 & 7.26 & 63.81 & 2.29 & 8.79 & 60.97 \\
6 & 1.37 & 5.26 & 69.07 & 2.11 & 8.10 & 69.07 \\
\hline
\end{tabular}

Table 4 showed the distribution of items for the six components that measured the selfcompassion construct consisting of SCS-MV1 to SCS-MV26. Component 1 - self kindness consisted of 5 items, component 2 - self-judgement also consisted of 5 items. Meanwhile, component 3 - common humanity and component 4 - isolation also consisted of 4 items respectively. Component 5 - mindfulness and component 6 - over-identification also 
TABLE 4: Distribution of self-compassion dimensions

Rotated Component Matrix and the components

\begin{tabular}{|c|c|c|c|c|c|c|}
\hline $\begin{array}{l}\text { Items/ } \\
\text { Components }\end{array}$ & 1 & 2 & 3 & 4 & 5 & 6 \\
\hline SCS-MV5 & 0.89 & & & & & \\
\hline SCS-MV12 & 0.95 & & & & & \\
\hline SCS-MV19 & 0.91 & & & & & \\
\hline SCS-MV23 & 0.88 & & & & & \\
\hline SCS-MV26 & 0.88 & & & & & \\
\hline SCS-MV1 & & 0.75 & & & & \\
\hline SCS-MV8 & & 0.85 & & & & \\
\hline SCS-MV11 & & 0.84 & & & & \\
\hline SCS-MV16 & & 0.83 & & & & \\
\hline SCS-MV21 & & 0.85 & & & & \\
\hline SCS-MV3 & & & & & - & \\
\hline SCS-MV7 & & & & & 0.82 & \\
\hline SCS-MV10 & & & & & 0.80 & \\
\hline SCS-MV15 & & & & & 0.81 & \\
\hline SCS-MV4 & & & & 0.72 & & \\
\hline SCS-MV13 & & & & 0.79 & & \\
\hline SCS-MV18 & & & & 0.73 & & \\
\hline SCS-MV25 & & & & 0.74 & & \\
\hline SCS-MV9 & & & & & & 0.80 \\
\hline SCS-MV14 & & & & & & 0.86 \\
\hline SCS-MV17 & & & & & & 0.79 \\
\hline SCS-MV22 & & & & & & - \\
\hline SCS-MV6 & & & 0.81 & & & \\
\hline SCS-MV2 & & & 0.65 & & & \\
\hline SCS-MV20 & & & 0.79 & & & \\
\hline SCS-MV24 & & & 0.75 & & & \\
\hline
\end{tabular}

**Extraction Method: Principal Component Analysis.

Rotation Method: Varimax with Kaiser Normalization.

a. Rotation converged in 6 iterations.

TABLE 5: Reliability of the instrument

\begin{tabular}{cccc}
\hline No. & Components/Subscales & $\begin{array}{c}\text { Number of } \\
\text { items }\end{array}$ & Cronbach's Alpha \\
\hline 1 & Component 1 & 5 & 0.95 \\
2 & Component 2 & 5 & 0.90 \\
3 & Component 3 & 4 & 0.79 \\
4 & Component 4 & 4 & 0.78 \\
5 & Component 5 & 3 & 0.78 \\
6 & Component 6 & 3 & 0.76 \\
1 to 6 & Total SCS-MV & 24 & 0.80 \\
\hline
\end{tabular}


consisted of 3 items each. Items of SCS-MV3 and SCS-MV22 did not represent any component and were removed due to low factor loadings. All items that represent each of the six components/subscales had weighting factors (Factor Loadings) exceeded the minimum limit of 0.60 .

Next, the reliability was examined using the Cronbach's Alpha to determine internal consistency of SCS-MV. The accepted value for Cronbach's Alpha should exceed the minimum limit of 0.7 (Awang, 2010; Hoque et al., 2016). Table 5 showed the Cronbach's Alpha values for all six components/subscales of SCS-MV, with all of them in the high range and exceeded the value of 0.75 . The total score for SCS-MV also demonstrated high Cronbach's Alpha of 0.80 . However, the SCS-MV only retained 24 items instead of 26 items as proposed by the original SCS (Neff, 2003).

\section{Discussion and Conclusion}

In the current study, we examined the psychometric properties of the Malay Version of SCS (SCS-MV) subscales and its total score. Our findings showed that the internal consistencies calculated using the Cronbach's alpha coefficients were high with a scores ranging from 0.76 to 0.95 . Item descriptions were examined in terms of means, standard deviations, skewness and kurtosis. Subsequent to data transformation, all the data showed good normality and kurtosis values. This study demonstrated that SCS-MV that comprised of six original SCS subscales were able to measure the self-compassion construct. However, 2 items from the original SCS were omitted as they did not load on any of the Malay translated version of selfcompassion subscales, hence leaving behind 24 items in SCS-MV. In conclusion, the Malay version of the SCS showed acceptable and adequate levels of internal consistency.

Results of EFA indicated that the SCS-MV conducted on Malaysian adolescents were able to retain the 6 components/subscales as originally postulated by Neff (2003). The SCSMV demonstrated excellent psychometric properties in which all items highly loaded on the expected factors. The validity of the SCS-MV also presented results in the expected directions and offered support to the external validity of the instrument. These results were consistent with the original SCS (Neff, 2003) and all other adapted as well as translated versions of the SCS (Cleare, Gumley, Cleare \& O’Connor, 2018; López et al., 2015; Neff, 2003; Raes, Pommier, Neff \& Van Gucht, 2011).

In sum, this study showed that the Self-Compassion Scales - Malay Version (SCS-MV) is indeed a valid and reliable measure to evaluate the self-compassion construct among a sample of young Malaysian population. This provides a good starting point for further research on other sub-groups such as adult population. Future research should also be be devoted to investigating the role of self-compassion construct on promoting psychological well-being among Malaysian population and possibly developing a model that shows the importance of self-compassion in influencing many aspects of our lives. For a start, future studies may need to confirm these initial findings and explore the new directions of selfcompassion construct and SCS-MV using more advance statistical analyses such as Confirmatory Factor Analysis (CFA) or Structural Equation Modelling (SEM).

This study may have some limitations. Firstly, data were gathered only from adolescents residing in the metropolitan area of Federal Terrritory, Kuala Lumpur. Results may not represent the true nature of Malaysian youth population as a large proportion of them resided in suburban or small town areas that span across the 14 states and 2 other federal territories in Malaysia. Secondly, all of the participants were 16 years old adolescents. This limitation was due to the ruling of EPRD, MOE which only allowed students who were not 
sitting for national examination to participate in any study. We had option to include the form 1 and form 2 students aged between 13 and 14 years old to be the study participants as they were also not involved in national examination. However, we decided to recruit the older adolecents to be the study participants since the questionnaire may be more appropriate for them. This assumption was based on the original development of SCS that used undergraduate samples (Neff, 2015). Taking these limitations in mind, future studies may need to recruit a large number of adolecents and young adults from a variety of settings so that results can be generalizable to larger population.

\section{Acknowledgement}

We would like to covey our special thanks to all the study participants, their parents, school management teams, EPRD MOE and everyone who were involved in this study. This study was part of a PhD research project conducted by the first author, Nor Azzatunnisak. The corresponding author, Dr Roseliza-Murni is the main supervisor of this project while the other two authors Dr Suzana and Dr Jamiah are the co-supervisors.

\section{References}

Allen, A. B., \& Leary, M. R. (2010). Self-Compassion, stress, and coping. Social and Personality Psychology Compass, 4(2), 107-118.

Awang, Z. (2014). A Handbook on Structural Equation Modeling. Bandar Baru Bangi: MPWS Rich Publication Sdn Bhd.

Awang, Z. (2015). SEM Made Simple: A gentle approach to learning Structural Equation Modeling. Bandar Baru Bangi: MPWS Rich Publication Sdn Bhd.

Awang, Z., Afthanorhan, A., \& Mamat, M. (2016). The Likert scale analysis using parametric based Structural Equation Modeling (SEM). Computational Methods in Social Sciences, 4(1), 13.

Beshai, S., Prentice, J. L., \& Huang, V. (2018). Building blocks of emotional flexibility: Trait mindfulness and self-compassion are associated with positive and negative mood shifts. Mindfulness, 9(3), 939-948.

Bluth, K., \& Blanton, P. W. (2015). The influences of self-compassion on emotional well-being among early and older adolescent males and females. The Journal of Positive Psychology, 10, 219-230.

Bluth, K., \& Neff, K. D. (2018). New frontiers in understanding the benefits of self-compassion. Self and Identity, 17(6), 605-608.

Choi, Y. M., Lee, D. G., \& Lee, H. K. (2014). The effect of self-compassion on emotions when experiencing a sense of inferiority across comparison situations. Procedia-Social and Behavioral Sciences, 114, 949-953.

Cleare, S., Gumley, A., Cleare, C. J., \& O'Connor, R. C. (2018). An investigation of the factor structure of the Self-Compassion Scale. Mindfulness, 9(2), 618-628.

Costa, J., Marôco, J., Pinto-Gouveia, J., Ferreira, C., \& Castilho, P. (2016). Validation of the psychometric properties of the Self-Compassion Scale. Testing the factorial validity and factorial invariance of the measure among borderline personality disorder, anxiety disorder, eating disorder and general populations. Clinical Psychology and Psychotherapy, 23(5), 460-468.

Deniz, M., Kesici, Ş., \& Sümer, A. S. (2008). The validity and reliability of the Turkish version of the Self-Compassion Scale. Social Behavior and Personality: An International Journal, 36(9), 1151-1160. 
Department of Statistics Malaysia. (2016). GDP by state: National accounts, 2010-2015. Putrajaya: Department of Statistics Malaysia

Garcia-Campayo, J., Navarro-Gil, M., Andrés, E., Montero-Marin, J., López-Artal, L., \& Demarzo, M. M. P. (2014). Validation of the Spanish versions of the long (26 items) and short (12 items) forms of the Self-Compassion Scale (SCS). Health and Quality of Life Outcomes, 12(1), 1.

Harwati, H., Melor, M. Y., \& Mohamed Amin, E. (2018). Measuring ELS learners' intention for using mobile learning: The development of instrument using EFA. Journal of Advance Research in Dynamical \& Control System, 10(2), 1696-1704.

Hollis-Walker, L., \& Colosimo, K. (2011). Mindfulness, self-compassion, and happiness in nonmeditators: A theoretical and empirical examination. Personality and Individual Differences, 50(2), 222-227.

Hoque, A. S. M. M., \& Awang, Z. (2016). The Exploratory Factor Analysis (EFA) of Entrepreneurial Marketing Scale - Development and Validation. Tourism Conference 20-22 APRIL 2016 (p. 22).

Karakasidou, E., Pezirkianidis, C., Galanakis, M., \& Stalikas, A. (2017). Validity, Reliability and Factorial Structure of the Self Compassion Scale in the Greek Population. Journal of Psychology and Psychotherapy, 7, 313.

Kaurin, A., Schönfelder, S., \& Wessa, M. (2018). Self-compassion buffers the link between selfcriticism and depression in trauma-exposed firefighters. Journal of Counseling Psychology, 65(4), 453.

Kelliher, R. J., Sirois, F. M., \& Hirsch, J. K. (2018). Self-compassion and suicidal behavior in college students: Serial indirect effects via depression and wellness behaviors. Journal of American College Health, 66(2), 114-122.

Kelvin, Y., \& Hashimah, M. H. I. (2016). Self-compassion, social connectedness and selfregulation of health behaviour: A preliminary study on local undergraduates in Malaysia. In $3^{\text {rd }}$ Kanita Postgraduate International Conference on Gender Studies, Universiti Sains Malaysia, Penang.

Leary, M. R., Tate, E. B., Adams, C. E., Batts Allen, A., \& Hancock, J. (2007). Self-compassion and reactions to unpleasant self-relevant events: the implications of treating oneself kindly. Journal of Personality and Social Psychology, 92(5), 887-904.

López, A., Sanderman, R., Smink, A., Zhang, Y., van Sonderen, E., Ranchor, A., \& Schroevers, M. J. (2015). A reconsideration of the Self-Compassion Scale's total score: selfcompassion versus self-criticism. PloS One, 10(7), e0132940.

Rahim, M. K., Rohany, N., Shahrazad, W. S., Waheeda, S. H., Atiqah, N. A., Rozainee, K., \& Zainah, A. Z. (2018). Validity and reliability of Malay version Financial Well-Being Scale among Malaysian Employees. Akademika, 88(2), 109-120.

Muhamud, S., Zaki, E. A., Zambri, C., Hanif, M. L., \& Zaizul, A. R. (2019). Using the Exploration Factor Analysis (EFA) to measure the validity and reliability for da'wah approach of jemaah tabligh. The Journal of Social Sciences Research, 5(4), 902-910.

Neff, K. D. (2003). The development and validation of a scale to measure self-compassion. Self and Identity, 2(3), 223-250.

Neff, K. D. (2016). The self-compassion scale is a valid and theoretically coherent measure of self-compassion. Mindfulness, 7(1), 264-274.

Neff, K. D., \& Costigan, A. P. (2014). Self-compassion, wellbeing, and happiness. Psychologie in Österreich, 2(3), 114-119. 
Neff, K. D., Tóth-Király, I., \& Colosimo, K. (2018). Self-compassion is best measured as a global construct and is overlapping with but distinct from neuroticism: A response to Pfattheicher, Geiger, Hartung, Weiss, and Schindler (2017). European Journal of Personality, 32(4), 371-392.

Azzatunnisak, N. M. K., Roseliza-Murni, A. R., Suzana, M. H., \& Jamiah, M. (2018). Kesahan dan kebolehpercayaan Instrument Skala Belas Kasihan Kendiri (SBKK) versi Bahasa Melayu. Jurnal Psikologi Malaysia, 32(3), 35-46.

Raes, F., Pommier, E., Neff, K. D., \& Van Gucht, D. (2011). Construction and factorial validation of a short form of the Self-Compassion Scale. Clinical Psychology \& Psychotherapy, 18(3), 250-255.

Fardaniah, S. A. A. (2016). Evaluating training effectiveness using the Malaysian sample: Tracing the moderation effect of training motivation using SEM-AMOS. International Journal of Economics and Financial Issues, 6(S6), 94-100.

Sirois, F. M. (2014). Procrastination and stress: Exploring the role of self-compassion. Self and Identity, 13(2), 128-145.

Suwaibah, Z., Suzana, M. H., Roseliza-Murni, A. R. \& Zainah, A. Z. (2016). Exploratory Factor Analysis (EFA) bagi Parental Sleep Attitude Scale versi Bahasa Melayu. e-Bangi Journal of Social Sciences and Humanities, Special Issue 2, 173-184.

Tabachnick, B. G., Fidell, L. S., \& Ullman, J. B. (2007). Using Multivariate Statistics (Vol. 5). Boston, MA: Pearson.

Terry, M. L., \& Leary, M. R. (2011). Self-compassion, self-regulation, and health. Self and Identity, 10(3), 352-362.

Voon, S. P., Lau, P. L., Leong, K. E. (2017). A Review on self-compassion and psychological wellbeing among counselors in Malaysia. International Journal of Education, Psychology and Counseling, 2(6), 46-56 